\title{
MENTAL DEPRESSION OF HIGHER SECONDARY STUDENTS
}

\author{
VENKATARAMAN S \& MANIVANNAN S \\ Assistant Professor, Department of Education, Annamalai University, Annamalai Nagar,
}

Chidambaram, Tamil Nadu-608002, India

\begin{abstract}
The present intended to find out Mental Depression of Higher Secondary Students. The investigation was undertaken by using normative survey method. The present study consists of 200 Higher secondary students studying in Nagappattinam district of Tamil Nadu. The sample was selected by using simple random sampling technique. For the present investigation, the researcher used the tool constructed and validated by L.N. Dubey (1993) to asses the Mental Depression of Higher Secondary students. The findings of the study reveal that the recent position of higher secondary schools student's mental depression is at a moderate state.

KEYWORDS: Mental Depression, Higher Secondary Students
\end{abstract}

Received: Apr 10, 2018; Accepted: May 26, 2018; Published: Jun 13, 2018; Paper Id.: IJEEFUSJUN20185

\section{INTRODUCTION}

For much of the day, depression is a disorder characterised by sorrow, emptiness, hopelessness, and lack of interest (American Psychiatric Association, 2013). Other symptoms can include: severe weight loss or gain, insomnia or hypersomnia, energy fatigue/loss, psychomotor agitation or retardation, feeling useless, excessive remorse, inability to focus, death thoughts, and ideation of suicide (American Psychiatric Association, 2013). For two-week duration or longer, five of the signs must be notable and cause deterioration in functioning to meet the requirements for a depressive disorder.

In addition, some of the depressive symptoms are things that can have a negative effect on the functioning of academia. During class, sleep disturbances and exhaustion can make it hard to show up or stay awake. For a student to be able to maintain knowledge and do well in his/her classes, lack of interest and perpetual feelings of sadness can be obstacles. The American Psychiatric Association (2013) notes that those engaged in cognitively demanding activities are often unable to operate... a steep drop in 14 grades may reflect poor concentration" (p. 164). Such signs and consequences suggest an association between depression and low academic performance.

The American College Health Association (2013) estimated that 14\% of college campus students reported depression over the past year as impacting their functioning. Seven percent of the population of the United States has undergone a major depressive disorder that lasts for 12 months or longer (American Psychiatric Association, 2013). This information suggests that depression exists at twice the rate of the average population among college students.

The prevalence of this disease is three times higher than among people who are sixty years and older, from the age of eighteen to twenty-nine. Traditional college students fall within the age range of eighteen to twenty-nine, and are thus at a much higher risk of depression. Depression levels in older students appear to rise. Depression is more common among women, and the risk of suicide attempts is higher, but suicide completion is lower than the 
rate for men (American Psychiatric Association, 2013). The Diagnostic and Statistical Manual of Mental Disorders currently has no clear culture-related diagnostic problems. However, in a study by Holliday et al. (2016), as compared to non-Hispanic female college students, both depression and anxiety were found to be more prevalent among Hispanic female students.

Depression (major depressive disorder) is a serious and severe medical condition that affects how you feel, how you think, and how you behave negatively. It is also, thankfully, treatable. When enjoyed, depression triggers feelings of distress and/or a lack of interest in hobbies. It can contribute to a number of emotional and physical issues and can reduce the ability of an individual to function at work and at home.

Depression symptoms can vary from mild to severe and can include:

- Feeling sad or having a depressed mood

- Loss of interest or pleasure in activities once enjoyed

- Changes in appetite - weight loss or gain unrelated to dieting

- Trouble sleeping or sleeping too much

- Loss of energy or increased fatigue

- Increase in purposeless physical activity (e.g., hand-wringing or pacing) or slowed movements and speech (actions observable by others)

- Feeling worthless or guilty

- Difficulty thinking, concentrating or making decisions

- Thoughts of death or suicide

Symptoms must last at least two weeks for a diagnosis of depression. Also, medical conditions can mimic symptoms of depression so it is important to rule out general medical causes.

\section{SEASONAL AFFECTIVE DISORDER}

Seasonal affective disorder* is a form of depression also known as SAD, seasonal depression or winter depression. People with SAD experience mood changes and symptoms similar to depression. The symptoms usually occur during the fall and winter months when there is less sunlight and usually improve with the arrival of spring. The most difficult months for people with SAD in the U.S. tend to be January and February. While it is much less common, some people experience SAD in the summer.

SAD is more than just "winter blues." The symptoms can be distressing and overwhelming and can interfere with daily functioning. However, it can be treated. About 5 percent of adults in the U.S. experience SAD and it typically lasts about 40 percent of the year. It is more common among women than men.

SAD has been linked to a biochemical imbalance in the brain prompted by shorter daylight hours and less sunlight in winter. As seasons change, people experience a shift in their biological internal clock or circadian rhythm that can cause them to be out of step with their daily schedule. SAD is more common in people living far from the equator where there are fewer daylight hours in the winter. 


\section{DEPRESSION AND SUICIDE}

A small proportion of depressed students show serious thoughts of planning or attempting suicide. Although the risk of suicide is higher with depressed students, the vast majority of them do not attempt it. Nevertheless, any signs of suicide should be taken seriously, even if they appear to be meaningless gestures. Because actual suicide attempts are infrequent and often are the result of specific situations, they are difficult to predict.

Suicidal thoughts are more likely when the student feels that nothing will help to improve the situation. Signs may be indirect, such as giving away personal or prized possessions, making statements about "not being around," visiting friends and family not seen recently, taking care of personal matters (e.g., repaying debts, completing unfinished tasks), and talking about how they would like to be remembered.

School children around the country have been shown to have a high incidence of mental health issues. There were inadequate opportunities in Chhattisgarh State for mental health services, counselling or alternative therapies to assist students and control their level of depression, stress and academic anxiety (Pandey, 2016). In the regional background, few mental health studies have been found to bridge the gap and discover the connection between anxiety, depression and stress with academic achievement.

Many factors have impacted the academic performance of students. A number of inputs have been reported in literature that affect academic achievement of students, including teacher support in the classroom setting (Sharma, 2014). Some characteristics of students and their families are also significant, including education for parents (Sharma \&Jha, 2016), locality and gender (Sharma, 2016). This research focuses on another factor that affects academic performance, i.e. anxiety, depression and stress. Literature predicts that depression and anxiety are correlated negatively with academic achievement.

Academic anxiety is a common psychosocial disorder in school going students. But most of the cases academic anxiety could be underestimated (Tomb \& Hunter, 2004); it's linked with perceived social support. Over anxiety associated with lower academic achievement. Parents' high educational expectations are one of the most negative factor for poor academic achievement and committed self harm activities. The teachers, counselors, administrators, and peers are all school setting can be a first line of defense for students in dealing with mental health concerns and to bring awareness to anxiety, stress and educate helpful ways to cope stress and anxiety.

\section{REVIEW OF RELATED LITERATURE}

Nativio G, Allison Let al (2014). A research to classify the signs of depression in students in school settings was conducted by. To diagnose depression in middle school/high school-age children in selected urban schools, researchers used the Patient Health Questionnaire-9 item. For further assessment and referral, students with positive screenings were referred to the multidisciplinary school-based Student Assistance Program team. The study concluded that by expediting the connection to care, these screenings increased the detection and referral of children suffering from depression for treatment.

Brunet, Sabiston M et al (2014) investigated the measurement invariance during adolescence of the depressive symptoms scale (DSS). The Nicotine Dependency in Teens (NDIT) study, an ongoing longitudinal cohort study of 1,293 adolescents, was used to obtain data. 527 participants who provided full data were included in the analytical study. Confirmatory factor analysis found that the best fit was supplied by an inter-correlated three-factor model of somatic, 
depressive, and anxiety variables. Finally, the DSS Time3 scores associated substantially with the symptoms of depression and anxiety assessed at Time 4. The study concluded that in somatic, depressive, and anxiety symptoms, the DSS is a multidimensional and appropriate method to investigate sex differences.

A cross-sectional survey on the prevalence and associations of depression among Chinese adolescents was conducted by Guo L, Deng J et al (2014). A total of 3186 students were sampled from schools in Guangdong in grades 7 12. In selecting the campuses, a stratified-cluster random-sampling technique was used. Depression was assessed using the Center for Epidemiology Scale for Depression (CES-D). Results showed that the mean student CES-D score was 15.2 ( \pm 9.4$)$ points, and 6.4 percent of students had depressive symptoms, and 2.47 (95 percent CI 1.61 to 3.79) times more likely to suffer from sleep disorder were students who had depressive symptoms.

A cross-sectional research on the prevalence and socio-demographic correlates of depression among students in Kenya was carried out by Othieno CJ, Okoth RO et al (2014). A random sample of 923 (525 male and 365 female) Nairobi students were interviewed. Depressive symptoms were assessed using the Short Depression Scale Centre for Epidemiological Research (CES-D 10). Results indicate that the total incidence of mild depressive symptoms was $35.7 \%$ (33.5\% males and 39.0\% females) and 5.6\% of extreme depression (5.3 percent males and 5.1 percent female).

A cluster randomised controlled trial of a universal Internet-based prevention programme for depression and anxiety among students was performed by Teesson, Newton C et al (2014). In New South Wales, Western Australia and Queensland, Australia, participants consisted of 8400 students aged 13 to 14 years from 84 secondary schools. The schools were one of four classes randomised into a cluster. For depression, researchers used the Patient Wellbeing Questionnaire (PHQ-8) and Anxiety Disorder 7-item Scale (GAD-7). The findings showed that there was a decreased incidence of depression and anxiety.

A randomised clinical trial on depression among school students from Santiago, Chile was performed by Araya, Fritsch et al (2013). There were a total of 2512 high school students from 22 schools and 66 grades. Depression was assessed at 3 months (primary) and 12 months (secondary) after completing the intervention by using Beck Depression Inventory-II. The findings revealed that the control group had 1291 participants and the intervention group had 1221. There was no indication of any clinically meaningful difference between the groups in mean depression scores (adjusted mean difference, $-0.19 ; 95 \% \mathrm{CI},-1.22$ to 0.84 ) or for any of the other results 3 months after the intervention was completed. At 12 months, no major variations were observed in any of the outcomes.

Auerbach, Webb P et al (2013) recorded that major depressive disorder has a substantial effect on the developmental trajectory of adolescents as well as adults, and depression models of cognitive vulnerability have led to the understanding of depression onset, maintenance, and recurrence. Selective, cognitive, the study revealed that

Vulnerability factors that are involved in youth and adult depression. Nguyen DT, Dedding C et al (2013) performed a cross-sectional analysis among Vietnamese high school students on depression, anxiety, and suicidal ideation. The sample size was 1161 high school students and the Center for Epidemiology Studies Depression Scale was used to assess depression. The results showed that the prevalence of depression was $41.1 \%$.

A randomised controlled trial was carried out by Rasing PA, Creemers HM et al (2013) to test a programme for the prevention of depression and/or anxiety over a 12-month follow-up period in high-risk adolescents. The experimental $(\mathrm{N}=80)$ or control groups $(\mathrm{N}=80)$ were randomly allocated to adolescents between 11 and 15 years of age with 
depressive/anxiety symptoms and parents who displayed signs of parental psychopathology. Depression was assessed using the Inventory of Child Depression. The primary outcome was depressive symptoms, and the secondary outcome was symptoms of anxiety and parental influence, parental psychopathology, parental stress, and teenage depression and parental depressive symptoms.

Simmons B, Hetrick E et al (2013) carried out a qualitative analysis in Melbourne, Australia, to investigate the experiences and values of treatment decision-making among young people diagnosed with depressive disorders. Clinicians who offered care to young people aged 12-18 years with MDD were sampled. 22 The psychiatrist was chosen by a deliberate sampling procedure. Audio taped, transcribed verbatim and analysed using thematic analyses were interviews. A collective model of care decision making for adolescent depression is validated by the current evidence.

A longitudinal cohort study was conducted in Chile by Stapinski LA, Montgomery AA et al (2013) among secondary school students aged 12 to 18 years. Twenty two schools were chosen at random and the sample size was 2508 . Depression was measured using the Beck Depression Inventory and data were available at baseline for $99.9 \%(\mathrm{n}=2505)$ of participants, $82 \%(n=2061)$ at the 6-month evaluation, and $77 \%(n=1934)$ at the 18 -month evaluation. The results of the study showed that $35 \%$ of girls and $28 \%$ of boys had clinical depression.

Depression, self esteem, body esteem, and eating attitudes among African American adolescents were examined by Witherspoon, Latta et al (2013). Rosenberg Self Confidence Scale, Beck Depression Inventory, The Children's Version of the Eating Attitudes Test, and Body Esteem Scale for Adolescents were completed by a community survey of 235 adolescents (11-16 years) Results found that 11 percent of adolescents were above the clinical cut of depression and female adolescents in the fields of depressed mood, body image, and eating attitudes had poorer psychosocial functioning than males.

\section{NEED AND SIGNIFICANCE OF THE STUDY}

Depression is a state of mind in which one suffers from sadness; it is a common but important cause of mental illness such as depression and academic stress. Depression interrupts the processes of thinking, emotional reaction and everyday life activities of a person (Williams, 1984; Farby, 1980). There are many factors, such as suicidal thinking, cognition, loneliness, social isolation, and lack of peer support, that contribute to depression. If parents neglect all things, students become severely mentally ill. Everyone feels blue or sad sometimes, but these emotions are usually temporary and pass within a few days. This interferes with everyday life, regular functioning, and causes distress for both the person with the condition and those who care about him or her when a person has a depressive disorder. Depression is a serious yet severe condition, and in order to get better, most people who encounter it need care.

Most persons with a depressive disorder never seek treatment. But the vast majority will get better with therapy, including those with the most serious depression. The advancement of drugs, psychotherapies, and other approaches to treat people with this disabling condition has resulted in intensive research into the disease. The investigator therefore agreed to take up a study of Higher Secondary Students with Mental Depression. 


\section{OBJECTIVES OF THE STUDY}

The present study has the following objectives:-

- $\quad$ To find out the level of Mental Depression of Higher Secondary students

- To find out the significance of difference between Male and Female Higher Secondary students in their Mental Depression.

- To find out the significance of difference in the Mental Depression between Arts and Science Higher Secondary students.

- To find out the significance of difference in the Mental Depression between Rural and Urban Higher Secondary students.

- To find out the significance of difference in the Mental Depression of Higher secondary students with respect to their Parental Income (below Rs.10000/10001-20000/above Rs.20000).

- To find out the significance of difference in the Mental Depression among Higher Secondary students with respect to their Community (OC/BC/MBC/SC/ST).

- To find out the significance of difference in the Mental Depression between Nuclear and Joint family Higher Secondary students.

\section{HYPOTHESES OF THE STUDY}

- There is significant difference between Male and Female Higher Secondary students in their Mental Depression.

- There is significant difference in the Mental Depression between Arts and Science Higher Secondary students.

- There is significant difference in the Mental Depression between Rural and Urban Higher Secondary students.

- There is significant difference in the Mental Depression of Higher secondary students with respect to their Parental Income (below Rs.10000/10001-20000/above Rs.20000).

- There is significant difference in the Mental Depression among Higher Secondary students with respect to their Community (OC/BC/MBC/SC/ST).

- There is significant difference in the Mental Depression between Nuclear and Joint family Higher Secondary students.

\section{METHODOLOGY}

The present investigation was undertaken by using normative survey method.

\section{Sample of the Study}

The present study consists of 200 Higher secondary students studying in Nagappattinam district of Tamil Nadu. The sample was selected by using simple random sampling technique. 


\section{Tool Used}

For the present investigation, the researcher used the tool constructed and validated by L.N. Dubey (1993) to asses the Mental Depression of Higher Secondary students.

In order to find out the Mental depression of Higher secondary students, the mean and S.D have been calculated.

Table 1: The Mean and Standard Deviation of Mental Depression Scores of Higher Secondary Students

\begin{tabular}{|c|c|c|c|c|}
\hline Variables & Sub Sample & $\mathbf{N}$ & Mean & S.D \\
\hline \multicolumn{2}{|c|}{ Entire Sample } & 200 & 27.51 & 8.760 \\
\hline \multirow[b]{2}{*}{ Gender } & Male & 102 & 27.16 & 8.257 \\
\hline & Female & 98 & 27.89 & 9.282 \\
\hline \multirow{2}{*}{ Group } & Arts & 96 & 27.57 & 8.534 \\
\hline & Science & 104 & 27.46 & 9.004 \\
\hline \multirow{2}{*}{ Locality } & Rural & 117 & 28.31 & 8.702 \\
\hline & Urban & 83 & 26.40 & 8.771 \\
\hline \multirow{2}{*}{ Type of Family } & Nuclear & 50 & 25.92 & 8.446 \\
\hline & Joint & 150 & 28.05 & 8.825 \\
\hline
\end{tabular}

\section{Entire Sample}

It is evident from the above Table, that the calculated mean score of entire sample was 27.51 and the Standard Deviation value is 8.70, which indicates that the Higher Secondary Students' are having moderate level of Mental Depression. This level moderate Mental depression is recorded among all the demographic variables of the selected Sample.

\section{Null Hypothesis}

There is no significant difference between Male and Female Higher Secondary students in their Mental Depression.

In order to test the above Null Hypothesis, ' $t$ ' value is calculated.

Table 2: Showing the Significant Difference between Male and Female Students of Higher Secondary with Respect to their Mental Depression

\begin{tabular}{|c|c|c|c|c|c|c|}
\hline \multicolumn{2}{|c|}{ Sub Sample } & N & Mean & S.D & 't' Value & Significance at 0.05 level \\
\cline { 1 - 5 } Gender & Male & 102 & 27.16 & 8.257 & \multirow{2}{*}{0.588} & Not Significant \\
\cline { 2 - 4 } & Female & 98 & 27.89 & 9.282 & \\
\hline
\end{tabular}

From the above table, since the ' $t$ ' value is not significant at 0.05 level, the null hypothesis is accepted and it is concluded that there is no significant difference between Male and Female Higher Secondary students in their Mental Depression.

\section{Null Hypothesis}

There is significant difference in the Mental Depression between Arts and Science Higher Secondary students.

In order to test the above Null Hypothesis ' $t$ ' value is calculated.

Table 3: Showing the Significant Difference between Arts and Science Group Students with Respect to their Mental Depression

\begin{tabular}{|c|c|c|c|c|c|c|}
\hline \multicolumn{2}{|c|}{ Sub Sample } & N & Mean & S.D & 't' Value & Significance at 0.05 Level \\
\cline { 1 - 5 } \multirow{2}{*}{ Group } & Arts & 96 & 27.57 & 8.534 & \multirow{2}{*}{0.90} & \multirow{2}{*}{ Not significant } \\
\cline { 2 - 5 } & Science & 104 & 27.46 & 9.004 & & \\
\hline
\end{tabular}


From the above table, since the ' $t$ ' value is not significant at 0.05 level, the Null Hypothesis is accepted and it is concluded that there is no significant difference in the Mental Depression between Arts and Science Higher Secondary students.

4.06.03. Analysis of mean scores of rural and urban Higher Secondary Students with respect to their Mental depression

\section{Null Hypothesis}

There is significant difference in the Mental Depression between Rural and Urban Higher Secondary students.

Table 4: Showing the Significant Difference between Rural and Urban Higher Secondary Students with Respect to their Mental Depression

\begin{tabular}{|c|c|c|c|c|c|c|}
\hline \multicolumn{2}{|c|}{ Sub Sample } & N & Mean & S.D & ' $\mathbf{t}$ ' Value & Significance at 0.05 Level \\
\cline { 1 - 6 } \multirow{2}{*}{ Locality } & Rural & 117 & 28.31 & 8.702 & \multirow{2}{*}{1.522} & Not significant \\
\cline { 2 - 5 } & Urban & 83 & 26.40 & 8.771 & \\
\hline
\end{tabular}

From the above table, since the ' $t$ ' value is not significant at 0.05 level, the Null Hypothesis is accepted and it is concluded that there is no significant difference in the Mental Depression between Rural and Urban Higher Secondary students..

\section{Null Hypothesis}

There is significant difference in the Mental Depression between Nuclear and Joint family Higher Secondary students.

In order to test the above Null Hypothesis ' $t$ ' value is calculated.

Table 5: Showing the Significant Difference between Nuclear and Joint Family Higher Secondary Students with Respect to their Mental Depression

\begin{tabular}{|c|c|c|c|c|c|c|}
\hline \multicolumn{2}{|c|}{ Sub Sample } & N & Mean & S.D & 't' Value & Significance at 0.05 Level \\
\hline \multirow{2}{*}{ Type of Family } & Nuclear & 50 & 25.92 & 8.446 & \multirow{2}{*}{1.524} & \multirow{2}{*}{ Not Significant } \\
\cline { 2 - 5 } & Joint & 150 & 28.05 & 8.825 & & \\
\hline
\end{tabular}

From the above table, since the ' $t$ ' value is significant at 0.05 level, the null hypothesis is accepted and it is concluded that there is no significant difference in the Mental Depression between Nuclear and Joint family Higher Secondary students.

\section{IMPORTANT FINDINGS}

The following are the important findings of the present study:

- The Higher Secondary Students' are having moderate level of Mental Depression

- There is no significant difference between Male and Female Higher Secondary students in their Mental Depression.

- There is no significant difference in the Mental Depression between Arts and Science Higher Secondary students.

- There is no significant difference in the Mental Depression between Rural and Urban Higher Secondary students.

- There is no significant difference between below Rs.10000 and above 20000 Parental Income sub samples of Higher Secondary Students in their mental depression and there is significant difference between, below 10000 \& 10001-20000 and 10001-20000 \& above 20000, Parental Income sub samples of Higher Secondary Students. 
- There is no significant difference in the Mental Depression among Higher Secondary students with respect to their Community (OC/BC/MBC/SC/ST).

- There is no significant difference in the Mental Depression between Nuclear and Joint family Higher Secondary students.

\section{CONCLUSIONS}

The present study made on higher secondary schools student's mental depression. The findings of the study reveal that the recent position of higher secondary schools student's mental depression is at a moderate state. By concentrating on Students' Psycho-Social needs their depression can be kept in control. For a depression free education system for the students, Government, Teachers, Parents' and Students should work together for mutually agreed solutions.

\section{REFERENCES}

1. American Psychiatric Association. (2013). Diagnostic and statistical manual of mental disorders (5th ed.). Arlington, VA: American Psychiatric Publishing.

2. Allison, L., Donna, G., Mitchell, M., DianxuRen., Yuhasz, M., (2014) "Identifying Symptoms of Depression and Anxiety in Students in the School Setting," The J. of School Nursing ., 30 (3), 165-172.

3. Allison, S., Roeger, L., Martin, G., Keeves, J., (2001) "Gender differences in the relationship between depression and suicidal ideation in young adolescents," Australia and NewZealand J. of Psychiatry., 35(4), 498-503.

4. Brunet.,Sabiston, M., Chaiton., Low, C. P., Conreras., Barnett, A., et al.,(2014) "Measurement invariance of the depressive symptoms scale during adolescence, "BMC Psychiatry., 14, 95.

5. Guo, L., Deng, J., He, Y., Deng, X., Huang, J., Huang, G., Gao, X., Lu, C., (2014) "Prevalence and correlates of sleep disturbance and depressive symptoms among Chinese adolescents: a cross-sectional survey study, "BMJ Open., 4(7).

6. Nguyen, D.T., Dedding, C., Pham, T.T., Wright, P., Bunders, J., (2013), "Depression, anxiety, and suicidal ideation among Vietnamese secondary school students and proposed solutions: a cross-sectional study," BMC Public Health., 13, 1195.

7. Othieno, C. J., Okoth, R. O., Peltzer, K., Pengpid, S., Malla, L.O., (2014), "Depression among university students in Kenya: Prevalence and sociodemographic correlates, "J. Affective Disorders., 165, 120-125.

8. Rasing, P. A., Creemers, H. M., Janssens.,Scholte, H. J., (2013), "Effectiveness of depression and anxiety prevention in adolescents with high familial risk: Study protocol for a randomized controlled trial," BMC Psychiatry., 13, 316.

9. Simmons, B., Hetrick, E., Jorm, F., (2013), "Making decisions about treatment for young people diagnosed with depressive disorders: A qualitative study of clinician's experiences," BMC Psychiatry., 13, 335.

10. Stapinski, L. A., et al., (2013), "Depression symptom trajectories and associated risk factors among adolescents in Chile," Plos ONE, 8(10).

11. Thirunavalavan, T, \& Venkataraman, S. (2017), Higher Secondary Students' Achievement in Chemistry, their Self-esteem, Self-Actualization and certain External Factors, International Journal of Academic Research Reflector 6 (5), 60-66.

12. Senthuran, D, \&Venkataraman, S. (2017), Personal, peer and parents' psychological factors and higher secondary students' achievement in zoology, International Journal of Innovative Research Explorer 6 (2), 53-56.

13. Senthuran, D, \& Venkataraman, S. (2017), Construction and validation of the State of External Factor Scale (SEFS), International Journal of Innovative Research Explorer 6 (1), 10-15. 
14. Senthuran, D, \& Venkataraman, S. (2017), Construction and validation of a tool measuring the personal peer and parents' psychological factors of higher secondary students, International Journal of Academic Research Reflector 6 (2), 16-21.

15. Venkataraman, S. (2016), Views on New Education Policy framework-2016 with regard to Curriculum Renewal, Examination Reforms and Governance Reforms in Higher Education, Research Inspiration 4 (1), 91-95.

16. Venkataraman, S. (2016), Views on New Education Policy framework-2016 with Regard to Restoration of Detention Policy between Class Six to Nine, Merger and Consolidation of Schools, International Journal for Research in Education (IJRE) 5 (3), 14-16.

17. Venkataraman, S. (2016), A study on profile update status of teaching staff in Annamalai University Website, Journal of Contemporary Educational Research and Innovations 5 (3), 157-160.

18. Venkataraman, S. (2016), Study on the data of Newly selected assistant professors for Tamil and English subjects for Arts and Science colleges of Tamilnadu, International Journal of Innovative Research Explorer 4 (1), 27-29.

19. Witherspoon., et al., (2013), "Do depression, self esteem, body esteem, and eating attitudes vary by BMI among African American adolescents, ”J. of Pediatric Psychology., 38(10), 1112-1120. 